\title{
Emprego de corretivos químicos, fontes e doses de fósforo em solo degradado por sais na produção do milheto (Pennisetum glaucum L.)
}

\author{
Use of chemical correctives, sources and levels of phosphorus in soil \\ degraded by salts on millet production (Pennisetum glaucum L.)
}

\author{
José Carlos de Menezes Júnior ${ }^{[a]}$, Rivaldo Vital dos Santos ${ }^{[b]}$, \\ Wladimir Nicolau Sobrinho ${ }^{[\mathrm{c}]}$, Jacob Silva Souto ${ }^{[\mathrm{d}]}$
}

[a] Zootecnista, Mestre em Sistemas Agrosilvopastoris no Semi-Árido pela Universidade Federal de Campina Grande (UFCG), câmpus de Patos, Campina Grande, PB - Brasil, e-mail: jcmenezesji@@hotmail.com

${ }^{[b]}$ Engenheiro Agrônomo, Doutor em Agronomia pela Escola Superior de Agricultura Luiz de Queiroz, Universidade Federal de Campina Grande (UFCG), câmpus de Patos, Campina Grande, PB - Brasil, e-mail: rvital@cstr.ufcg.edu.br

${ }^{[c]}$ Zootecnista, com Mestrado pela Universidade Federal de Campina Grande (UFCG), câmpus de Patos, Campina Grande, PB Brasil, e-mail: wladimirnicolau@hotmail.com

[d] Engenheiro agrônomo, Doutor em Agronomia (Agricultura) pela Universidade Estadual Paulista Júlio de Mesquita Filho (UNESP), Universidade Federal de Campina Grande (UFCG), câmpus de Patos, Campina Grande, PB - Brasil, e-mail: jacob_souto@yahoo.com.br

\section{Resumo}

A correção de solos com problema de salinidade requer, além da redução da concentração de sais solúveis e do sódio no perfil do solo, o aumento da fertilidade visando a produções satisfatórias. O objetivo do trabalho foi avaliar o efeito de corretivos, fontes e doses de fósforo na produção do milheto cultivado em solo salino-sódico. O ensaio experimental foi desenvolvido em telado pertencente ao CSTR/UFCG, em Patos, PB. O solo utilizado no experimento proveio do Perímetro Irrigado de São Gonçalo, pertencente ao município de Sousa, PB. O experimento foi desenvolvido em um delineamento inteiramente casualizado no esquema fatorial $2 \times 2 \times 4$, referente aos corretivos (gesso e ácido sulfúrico), às fontes de fósforo (ácido fosfórico e superfosfato simples) e às doses de $\mathrm{P}(0,70,140$ e $210 \mathrm{mg} \mathrm{dm}$-3), com três repetições. Acondicionou-se o solo em vasos, permanecendo incubado após a aplicação dos corretivos durante 20 dias; em seguida, foi efetuada lavagem, e mais 20 dias após a adição das fontes fosfatadas. Logo depois, cultivou-se o milheto. As plantas de milheto cultivadas com gesso e o ácido fosfórico, dentre as fontes de fósforo utilizadas, foram as que apresentaram maior produção vegetativa.

(P)

Palavras-chave: Recuperação. Salinidade. Fertilidade. 


\begin{abstract}
Correction of the soil salinity requires, besides de reduction of soluble salts and sodium concentration in the soil profile, to increase fertility in order to get satisfactory production. This research had the objective to evaluate the effect of correctives, sources and levels of phosphorus in the millet production grown in saline-sodic soil. Experimental test was conducted in greenhouse belonging to the CSTR/ UFCG, in the city of Patos, PB. The soil used in the experiment came from the Irrigated Perimeter of São Gonçalo, belonging to the municipality of Sousa, PB. The experiment was conducted in a completely randomized design in a factorial $2 \times 2 \times 4$, regarding corrective (gypsum and sulfuric acid), sources of phosphorus (phosphoric acid and super simple) and P levels (0, 70, 140 and 210 $m g d m-3)$ with three replications. Soil was packed in pots, incubated remaining after application of correctives for 20 days, then done washing, and again 20 days after the addition of phosphate sources. Soon after, millet was cultivated. Millet plants cultivated with gypsum, phosphoric acid, among the phosphorous sources used, were those which showed higher vegetative production.
\end{abstract}

Keywords: Recovery. Salinity. Fertility.

\title{
Introdução
}

Normalmente, os solos afetados por sais são encontrados em zonas áridas e semi-áridas, em razão da alta taxa de evaporação e da baixa precipitação pluviométrica, associada a uma drenagem deficiente. Além dos solos naturalmente halomórficos, muitos são salinizados e/ou sodificados pelo homem. É comum o surgimento de problemas de salinidade em áreas irrigadas cujas técnicas de manejo não visem à aplicação suficiente de água e conservação da capacidade produtiva dos solos, bem como um eficiente sistema de drenagem, assim como o uso excessivo de fertilizantes (SILVA FILHO et al., 2000). O excesso de sais solúveis leva à redução do potencial osmótico da solução do solo, dificulta a absorção de água pela planta, causa desbalanço nutricional e afeta o desenvolvimento e produção das culturas.

A reabilitação desses solos requer a redução da concentração de sais solúveis e do sódio no perfil do solo, usualmente proporcionados pela aplicação de corretivos químicos, destacando-se o gesso e o ácido sulfúrico, seguida de lixiviação, num padrão não prejudicial ao desenvolvimento das culturas. Entretanto, assim como em solos normais, o fornecimento de um nível nutricional satisfatório é necessário para maximizar a produção das culturas em condições salinas. Todavia, há a necessidade de se aplicar fertilizantes que possam melhorar a fertilidade do solo, sem comprometer o processo de sua recuperação. Dessa forma, associada à correção do solo, a melhoria nutricional pode ser uma alternativa para aumentar a produtividade de culturas submetidas a ambientes salinizados (QADAR, 1998). Tratando-se da nutrição de fósforo, os resultados ainda não são muito claros, podendo variar conforme a salinidade, a concentração de P e a espécie estudada (GRATTAN; GRIEVE, 1998).

O milheto (Pennisetum glaucum (L.) R. Brown) é um dos cereais de maior importância no mundo, sendo considerado uma excelente alternativa para a produção de grãos e forragem, especial em regiões áridas ou semi-áridas em virtude de sua adaptação à seca e aos solos arenosos com baixo teor de matéria orgânica.

Apesar de produzir sob condição de baixa fertilidade, o milheto responde à fertilização dos solos. Essas propriedades evidenciam o potencial promissor do milheto como uma planta forrageira que pode ser usada estrategicamente na fase inicial da recuperação de terras degradadas. Graças ao rápido crescimento, o milheto mantém a área degradada protegida a partir dos 40 dias após o plantio. Diante do exposto, o milheto, dada sua palatabilidade, valor proteico e palhada, pode constituir uma alternativa para produção de silagem, principalmente em regiões com problemas de veranicos longos, ou até mesmo que apresentem aridez.

Sob esse aspecto, a definição de práticas de manejo que abordem a interação fertilidade e salinidade torna-se imprescindível para a eficácia do processo de recuperação. Nesse sentido, o trabalho teve como objetivo avaliar a aplicação de corretivos químicos e de fontes e doses de fósforo na produção de plantas de milheto. 


\section{Material e métodos}

O ensaio experimental foi desenvolvido em telado pertencente ao Centro de Saúde e Tecnologia Rural da Universidade Federal de Campina Grande (UFCG), câmpus de Patos, localizado na região semiárida do Estado da Paraíba. O solo foi coletado na profundidade de 0-30 cm no Perímetro Irrigado de São Gonçalo, no município de Sousa, PB, apresentando as seguintes características químicas: $\mathrm{pH}=10,57$; $\mathrm{CE}=$ $20,3 \mathrm{dS} \mathrm{m}^{-1} ; \mathrm{MO}=5,05 \mathrm{~g} \mathrm{~kg}^{-1} ; \mathrm{P}=10,64 \mathrm{mg} \mathrm{dm}^{3} ; \mathrm{K}=77,10 \mathrm{mg} \mathrm{dm}^{3}$; e Na, H+Al, Ca, Mg, SB e CTC, 21,2; 0,$0 ; 0,30 ; 0,15 ; 21,85 ;$ e $21,85 \mathrm{cmol}_{\mathrm{c}} \mathrm{dm}^{3}$ respectivamente, e $\mathrm{V}=100 \%$.

Para a correção da salinidade do solo, a necessidade de gesso foi quantificada a partir da modificação do método de Schoonover sugerido por Chauhan e Chauhan (1978), aplicando-se $34 \mathrm{~g} \mathrm{~kg}^{-1} \mathrm{de} \mathrm{gesso}(100 \%$ NG). Quanto à determinação da necessidade de ácido sulfúrico, um pré-ensaio foi instalado aplicando-se doses crescentes do ácido $\left(0 ; 1 ; 2 ; 3 ; 4 ; 5 ;\right.$ e $\left.6 \mathrm{~mL} \mathrm{~kg}^{-1}\right)$ em vasos contendo $1 \mathrm{~kg}$ de solo. Ao fim de 30 dias, analisando o solo em questão, observou-se que a dose do $\mathrm{H}_{2} \mathrm{SO}_{4}$, equivalente de $3,4 \mathrm{~mL} \mathrm{~kg}^{-1}$ de solo, foi suficiente para reduzir o pH deste para 6,5.

O experimento foi montado em um delineamento inteiramente casualizado no esquema fatorial $2 \times 2 \times 4$, com três repetições, correspondentes à incorporação dos dois corretivos, gesso e ácido sulfúrico, das duas fontes de fósforo, superfosfato simples e ácido fosfórico, e da aplicação de doses crescentes de P (0; 70; 140 e $210 \mathrm{mg} \mathrm{dm}^{-3}$ ). Após a aplicação dos corretivos, o solo permaneceu incubado por 20 dias. Logo em seguida, as fontes e doses equivalentes de fósforo foram aplicadas e incorporadas a $7 \mathrm{~kg}$ de solo e a mistura foi acondicionada em recipientes plásticos, permanecendo incubada por mais 20 dias.

A adubação básica consistiu na adição de $60 \mathrm{mg} \mathrm{kg}^{-1}$ de $\mathrm{N}$ e $70 \mathrm{mg} \mathrm{kg}^{-1} \mathrm{~K}_{2} \mathrm{O}$ no solo. No ato da semeadura, empregaram-se dez sementes de milheto (Pennisetum glaucum L.) por vaso, que foram semeadas. Oito dias após a emergência das plântulas e estabilização do processo germinativo, foi feito o desbaste, mantendo as duas plantas mais vigorosas em cada parcela experimental. Durante o período experimental foram aplicadas lâminas de água não salina, a partir da pesagem diária dos vasos, de modo a compensar as perdas por evaporação, visando a manter o conteúdo de água próximo a 70\% da capacidade de campo. Após 60 dias, computados a partir do desbaste das plântulas, foram avaliadas a altura $(\mathrm{cm})$, diâmetro $(\mathrm{mm})$, número de folhas e massa verde $(\mathrm{g})$ do milheto.

\section{Resultados e discussão}

No geral, comparando-se o emprego dos condicionadores químicos, as parcelas tratadas com gesso apresentaram maiores valores médios dos componentes de produção vegetal (Tabela 1). Tal comportamento pode ser atribuído possivelmente à melhoria física do solo, em função da incorporação do gesso, proporcionando, assim, melhor desenvolvimento do sistema radicular e, consequentemente, melhor nutrição e maior produção das plantas. Segundo Pimentel (1999), quanto mais desenvolvido é o sistema radicular, melhor será o desenvolvimento da parte aérea das plantas. Carvalho e Raij (1997) relatam que aplicação de gesso no solo seguida por lixiviação resulta em melhor desenvolvimento radicular e maior absorção de água e nutrientes pelas raízes das plantas, além da ação atenuante dos efeitos nocivos da salinidade. Vital (2002) verificou que o gesso exerceu efeito positivo sobre a disponibilidade de nutrientes, com aumentos significativos nos níveis de cálcio e fósforo no solo e no crescimento inicial do cajueiro anão precoce cultivado em solo salino-sódico.

Tabela 1 - Produção de massa verde, altura, diâmetro e números de folhas das plantas de milheto em função dos corretivos

\begin{tabular}{lllll}
\hline \multirow{2}{*}{ Corretivos } & \multicolumn{4}{c}{ Parâmetros vegetais avaliados } \\
\cline { 2 - 5 } Gesso & Massa verde $\left(\mathrm{g} \mathrm{vaso}^{-1}\right)$ & Altura $(\mathrm{cm})$ & Diâmetro $(\mathrm{mm})$ & Número de folhas \\
\cline { 2 - 5 } Ácido sulfúrico & $76,60 \mathrm{a}$ & $71,65 \mathrm{a}$ & $12,85 \mathrm{a}$ & $9,70 \mathrm{a}$ \\
\hline
\end{tabular}

Nota: Médias seguidas de mesma letra na coluna não diferem entre si pelo teste de Tukey a $5 \%$ de probabilidade. 
A produção de matéria verde da parte aérea, diâmetro e o número de folhas das plantas apresentaram diferenças significativas quanto às fontes de fósforo (Tabela 2). O uso de ácido fosfórico resultou em maior massa, tanto de matéria seca como de matéria verde da parte aérea do milheto, bem como a obtenção de maior número de folhas, provavelmente em resposta à presença de teores mais elevados de fósforo no solo, o que propiciou um maior crescimento as plantas. Esse efeito está diretamente associado à maior velocidade de liberação do nutriente pela maior solubilidade do ácido fosfórico, comparado ao superfosfato simples, uma vez que esse minimiza o efeito da competição solo-planta, pois, segundo Novais e Smith (1999), a fixação do fósforo pelos coloides do solo se dá de forma preferencial.

Tabela 2 - Produção de massa verde, altura, diâmetro e números de folhas das plantas de milheto em função de fontes de fósforo

\begin{tabular}{lllll}
\hline \multirow{2}{*}{$\begin{array}{l}\text { Fontes de } \\
\text { fósforo }\end{array}$} & Parâmetros vegetais avaliados \\
\cline { 2 - 5 } & Massa verde $\left(\mathrm{g} \mathrm{vaso}^{-1}\right)$ & Altura $(\mathrm{cm})$ & Diâmetro $(\mathrm{mm})$ & Número de folhas \\
\hline $\begin{array}{l}\text { Superfosfato } \\
\text { simples }\end{array}$ & $61,79 \mathrm{a}$ & $11,69 \mathrm{~b}$ & $8,89 \mathrm{~b}$ \\
Ácido fosfórico & $76,99 \mathrm{a}$ & $67,61 \mathrm{a}$ & $12,95 \mathrm{a}$ & $9,66 \mathrm{a}$ \\
\hline
\end{tabular}

Nota: Médias seguidas de mesma letra na coluna não diferem entre si pelo teste de Tukey a $5 \%$ de probabilidade.

Para as produções da massa verde (Figura 1), em ambas as fontes de fósforo estudadas, todas as doses diferiram da testemunha. Os dados obtidos ajustaram-se linearmente, indicando que as doses testadas não foram suficientes para atender à demanda das plantas. Quando comparados os resultados das fontes dentro de cada dose para as produções de massa vegetal verde, observa-se diferença significativa para as fontes de fósforo testadas, caracterizada pela maior eficiência da fonte ácido fosfórico na produção de biomassa vegetal das plantas de milheto. Esses resultados estão de acordo com os obtidos com Harger et al. (2007), exaltando que, independente da fonte, o incremento de doses de $\mathrm{P}$ aumentou a produção de biomassa vegetal das plantas de milho.

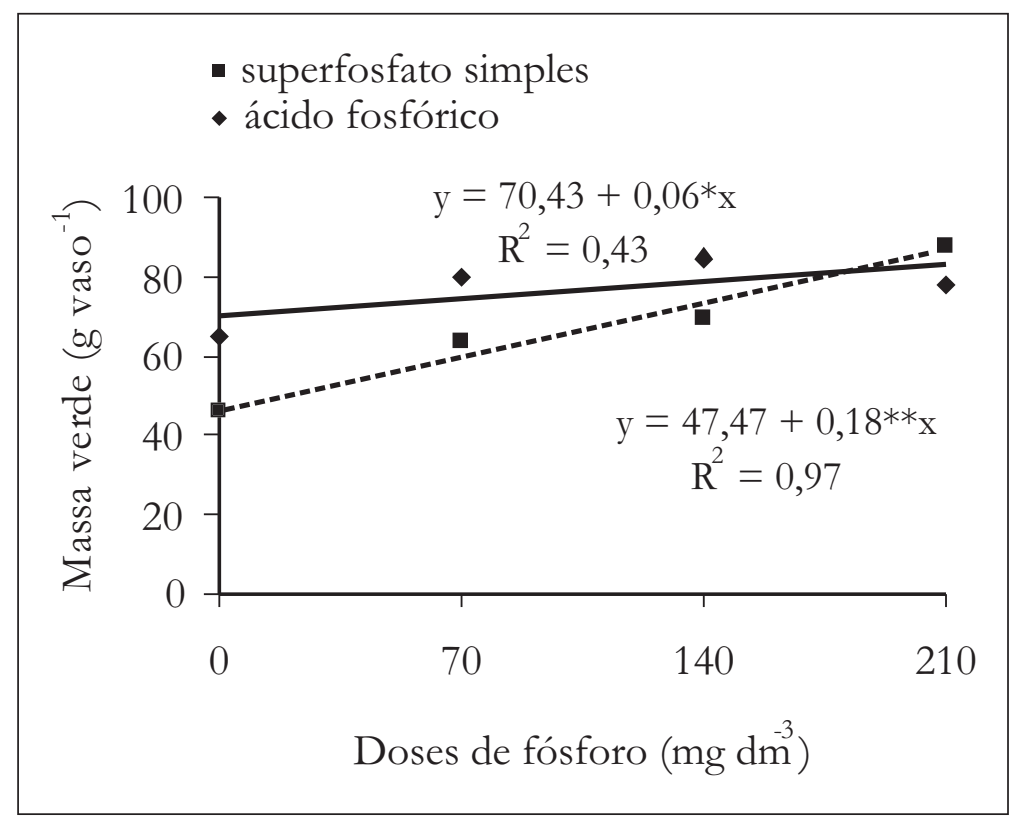

Figura 1 - Produção de massa verde do milheto em função de doses e fontes de fósforo 
Com relação à altura das plantas e o número de folhas obtidos a partir da fonte de ácido fosfórico, os dados não demonstraram tendência definida; o incremento das doses de fósforo não diferiu da testemunha, apresentando valor médio de 67,61 cm e 9,6 cm, respectivamente (Figuras 2 e 3). Todavia, a literatura relata que as plantas em geral utilizam com maior eficiência o fósforo quando é menor a disponibilidade, expressando, assim, a maior utilização do nutriente absorvido (ALVAREZ et al., 2002). Embora não se verifique ocorrência significativa das doses de fósforo no número de folhas com o emprego da fonte ácida, o valor médio obtido com esse tratamento é ligeiramente superior, comparando-se com a outra fonte de fósforo.

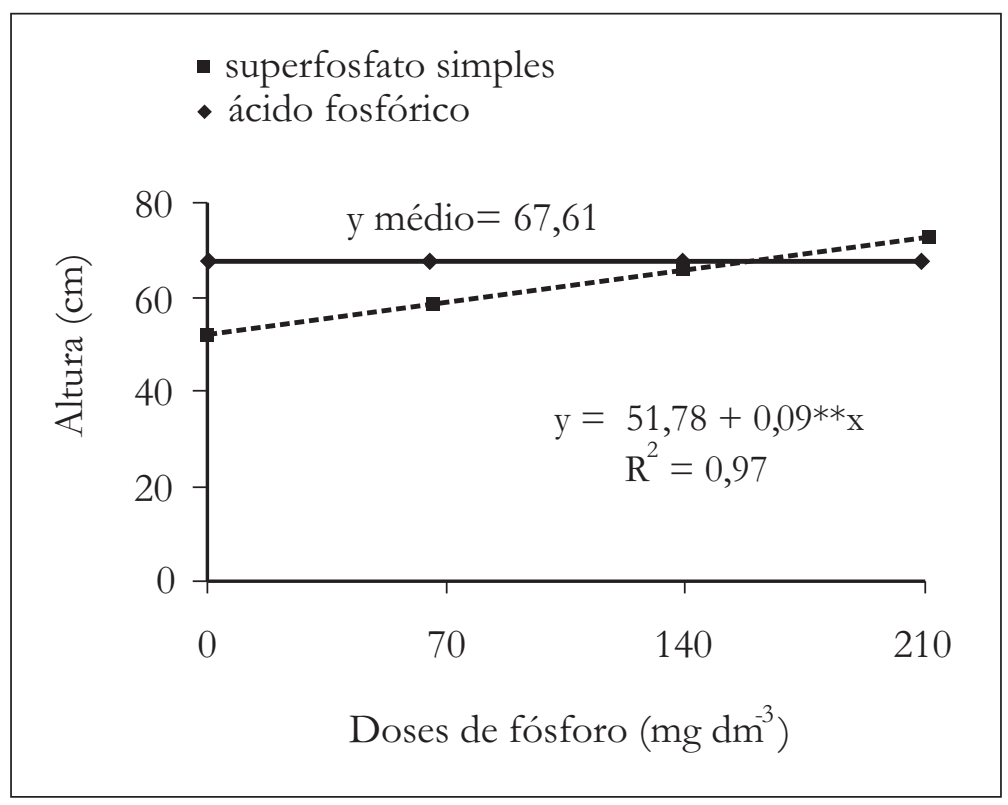

Figura 2 - Altura das plantas de milheto em função de doses e fontes de fósforo

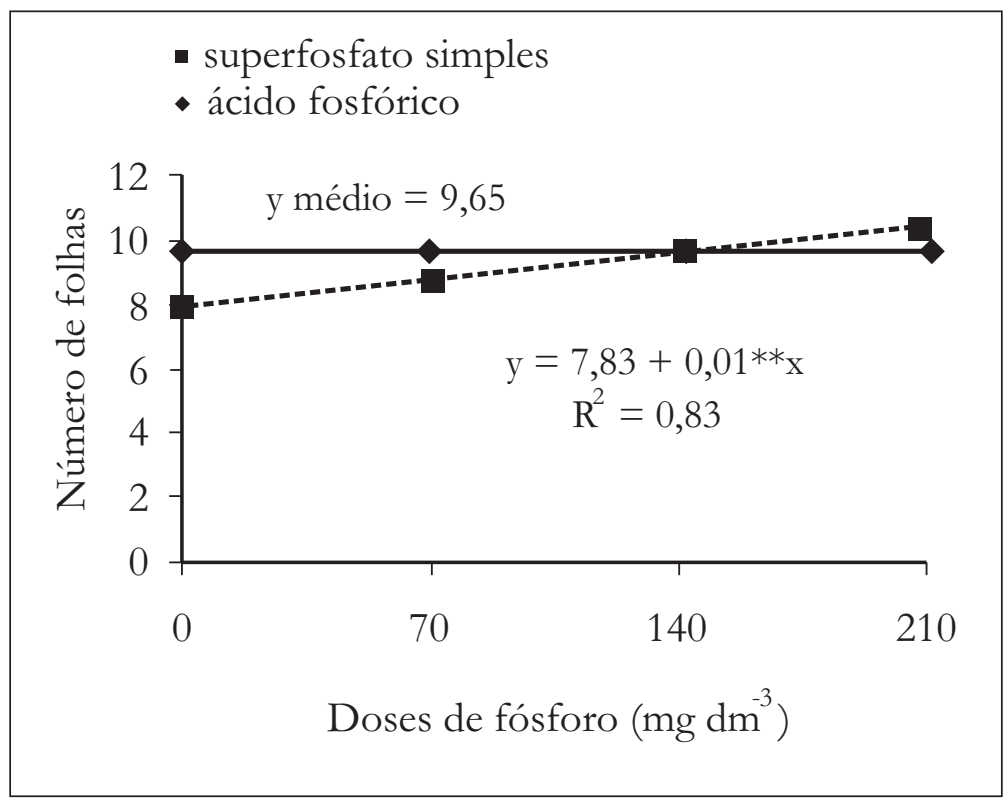

Figura 3 - Número de folhas das plantas de milheto em função de doses e fontes de fósforo 
Por outro lado, os valores médios de altura e número de folhas obtidos a partir do emprego do superfosfato simples apresentaram aumento linear, com o incremento das doses do adubo. Tal fato pode ser explicado pela menor reatividade do superfosfato simples em relação ao ácido fosfórico, disponibilizando, assim, mais lentamente o P e, dessa forma, poderia favorecer maior eficiência de utilização do nutriente pelas plantas (NOVAIS; SMITH, 1999).

Quanto ao diâmetro das plantas de milheto, os dados se ajustaram linearmente, independente da fonte utilizada, com o aumento das doses de fósforo (Figura 4). Observa-se também ligeira superioridade do ácido fosfórico em relação ao emprego do superfosfato simples. Lana et al. (2004), avaliando o uso de diferentes fontes de fósforo nas produções de alface, observaram variação entre as fontes testadas e, na ausência do fósforo, houve uma significativa redução no diâmetro das plantas.

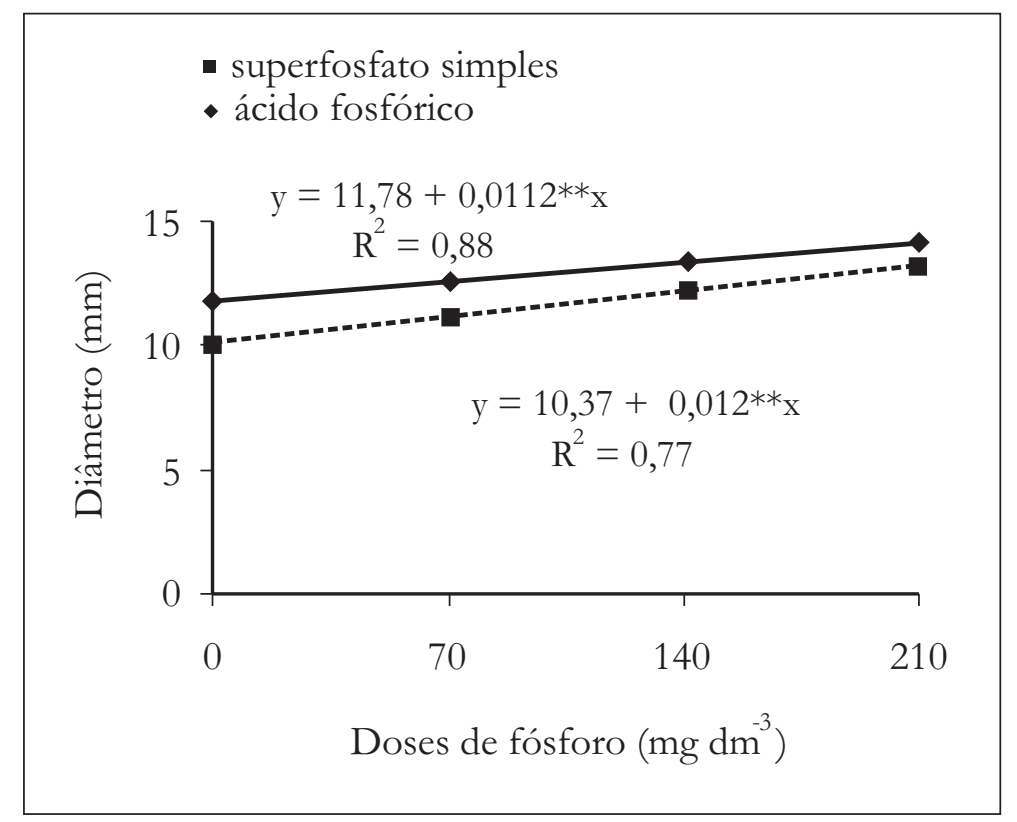

Figura 4 - Diâmetro das plantas de milheto em função de doses e fontes de fósforo

\section{Conclusão}

Para as condições de solo estudadas, o emprego de gesso como corretivo e, dentre as fontes de fósforo avaliadas, a aplicação de ácido fosfórico promoveram um maior crescimento das plantas de milheto, sendo recomendados para programas de recuperação de áreas degradadas por sais.

\section{Referências}

ALVAREZ, F. C. V. et al. Utilização de fósforo do solo e do fertilizante por tomateiro. Scientia Agrícola, v. 59, n. 1, p. 167-172, 2002.

CARVALHO, M. C. S.; RAIJ, B. van. Calcium sulphate, phosphogypsum and calcium carbonate in the amelioration of acid subsoils for root growth. Plant Soil, v. 192, n. 1, p. 37-48, 1997.

CHAUHAN, R. P. S.; CHAUHAN, C. P. S. A modification to Schoonover's method of gypsum requirement determination of soil. Australian Journal of Soil Research, v. 17, n. 2, p. 367-370, 1978. 
GRATTAN, S. R.; GRIEVE, C. M. Salinity-mineral nutrient relations in horticultural crops. Scientia Horticulture, v. 78, n. 1-4, p. 127-157, 1998.

HARGER, N. et al. Avaliação de fontes e doses de fósforo no crescimento inicial do milho. Semina: Ciências Agrárias, v. 28, n. 1, p. 39-44, 2007.

LANA, R. M. Q. et al. Produção da alface em função do uso de diferentes fontes de fósforo em solo de Cerrado. Horticultura Brasileira, v. 22, n. 3, p. 525-528, 2004.

NOVAIS, R. F.; SMITH, T. J. Fósforo em solo e planta em condições tropicais. Viçosa: UFV-DPS, 1999. p. 62-64.

PIMENTEL, N. S. Calcário: o multiplicador de pastagem. Panorama Rural, v. 1, n. 4, p. 59-62, 1999.

QADAR, A. Alleviation of sodicity stress on rice genotypes by phosphorus fertilization. Plant and Soil, v. 20, n. 3, p. 269-277, 1998.

SILVA FILHO, S. B. et al. Monitoramento da qualidade da água e acumulo de sais no solos pela irrigação. Revista Irriga, v. 5, n. 2, p. 112-125, 2000.

VITAL, A. de. F. M. Efeitos do gesso e do fósforo na disponibilidade de nutrientes e no desenvolvimento inicial do cajueiro em solo salino-sódico. 2002. 93 f. Dissertação (Mestrado em Manejo de Solo e Água) Universidade Federal da Paraíba, Centro de Ciências Agrárias, Areia, PB, 2002.

Recebido: 08/07/2009

Received: 07/08/2009

Aprovado: 22/12/2009

Approved: 12/22/2009 